\title{
Synthesis and Density Functional Theory Studies of Novel Heterocycle Tethered with Pyrazole and Benzimidazole Structural Motifs
}

\author{
Ramar Sivaramakarthikeyan, Krishnaraj Padmavathy, Shunmugam Iniyaval, \\ Chennan Ramalingan
}

\begin{abstract}
A novel heterocyclic chemical entity, 2-(1H-benzo[d]imidazol-2-yl)-3-(3-(4-nitrophenyl)-1-phenyl-1Hpyrazol-4-yl)acrylonitrile) (1f) has been synthesized and characterized. Computational studies were carried out using Gaussian 9 program with DFT/B3LYP/6311(++G) basis set. The structural optimization was computed successfully. Further, HOMO-LUMO analysis promises the incidence of inter electron transfer within the molecule. The theoretically determined hyperpolarizability value is nearly 9.5 times better than standard urea, suggesting its future utility as an efficient NLO optic material or its utility as an effective intermediate to construct better NLO materials.
\end{abstract}

Keywords: Pyrazole, Imidazole, DFT, NLO.

\section{INTRODUCTION}

In recent years, the application-oriented synthesis has become crucial. Heterocycles possessing nitrogen(s) and their analogues have been placed as paragon source in material sciences [1] and medicine [2]. Pyrazole is one among the nitrogen heterocycles with no exemption, its derivatives were proven to be vital in regard to wide spectrum of biological activities [3-10] exhibited by them. No wonder that numerous marketed drugs such as Celecoxib an anti-inflammatory drug, Rimonabant - a cannabinoid receptor, Fomepizole- prevents alcohol dehydrogenase and sildenafil that hinders phosphodiesterase [11] comprises of pyrazole scaffold. Besides astonishing biological applications of pyrazoles, their material science applications including brightening agents [12], noteworthy solvatochromic [13] electroluminescence [14], semiconductors [15], liquid crystals [16], OLEDs [17]

Revised Manuscript Received on December 17, 2019.

* Correspondence Author

Ramar Sivaramakarthikeyan, Department of Chemistry, School of Advanced Sciences, Kalasalingam Academy of Research and Education (Deemed to be University), Krishnankoil, 626 126, Tamilnadu, India. Email: sivaram.ramar@gmail.com

Krishnaraj Padmavathy, Department of Chemistry, School of Advanced Sciences, Kalasalingam Academy of Research and Education (Deemed to be University), Krishnankoil, 626 126, Tamilnadu, India. Email: ovshada@gmail.com

Shunmugam Iniyaval, Department of Chemistry, School of Advanced Sciences, Kalasalingam Academy of Research and Education (Deemed to be University), Krishnankoil, $626 \quad 126$, Tamilnadu, India. Email: iniyaval.s@klu.ac.in

* Chennan Ramalingan, Department of Chemistry, School of Advanced Sciences, Kalasalingam Academy of Research and Education (Deemed to be University), Krishnankoil, $626 \quad 126, \quad$ Tamilnadu, India. Email: ramalinganc@gmail.com and solar cells [18] are significant. On the other hand, benzimidazole forms the essential component in biological system. Akin to pyrazoles, benzimidazoles have enthralled the interest of application chemist owing to varied therapeutic applications [19]. Specifically, benzimidazoles have anti-infective [20]' antiviral [21] and male contraceptive [22] activities. Benzimidazole nucleus with diverse substituents has been observed in various drugs like omeprazole, lansoprazole, pantoprazole as proton pump inhibitors, astemizole as antihistaminic, and albendazole, mebendazole, thiabendazole as antihelmintics [23,24]. In fact, certain benzimidazoles were proved to act as acceptors in polymers which have been developed for electrochromic applications [25].

Considering the vast applications shown by both pyrazole and benzimidazole has initiated our keenness towards synthesis of single compound with both functionalities together with increased in conjugation so that the novel compound may find applications both in medicinal and material science field. Consequently, a novel heterocycle 1f has been synthesized by cost effective and simple multistep process. The structure of the molecule was supported based on analytical and spectroscopic methods. In addition, the quantum chemical parameters were achieved with the use of DFT.

\section{EXPERIMENTAL SECTION}

\section{A. General}

All reactants / reagents used in the present study are reagent grade and the solvents were distilled prior to use. Shimadzu IR Tracer-100 spectrophotometer and Bruker AVANCE III NMR spectrometer were utilized for recording IR and NMR spectra, respectively. TLC and open capillary were used to observe the reactions progress and to measure the melting point, respectively.

\section{B. Synthesis of carbaldehyde $1 d$}

A homogeneous mixture of 4-nitroacetophenone (0.01 $\mathrm{mol})$ and phenyl hydrazine $(0.01 \mathrm{~mol})$ in $5 \mathrm{ml}$ of glacial acetic acid was heated for 30 minutes. It was filtered, after cooling, and washed with dil. $\mathrm{HCl}$ to obtain the crude product 1c Recrystallization from ethanol rendered corresponding arylhydrazone 1c in pure form. The pure arylhydrazone thus obtained was then treated with

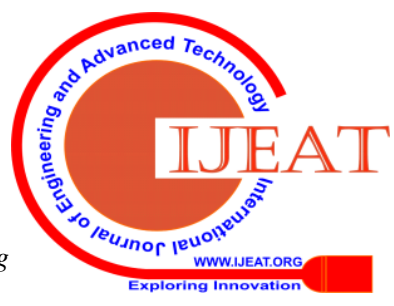




\section{Benzimidazole Structural Motifs}

cold Vilsmeier-Hacck reagent [(DMF $(10 \mathrm{ml})-\mathrm{POCl}_{3}(0.03$ mol)]. It was stirred at $70-80{ }^{\circ} \mathrm{C}$ for $6 \mathrm{~h}$. After ensuring the completion, it was brought to ambient temperature and then poured into water. The mixture was then neutralized using saturated solutions of sodium bicarbonate and the solid obtained was dried after filtration and washed with water to afford pure carbaldehyde 1d [26].

C. Synthesis of 2-(1H-benzo[d]imidazol-2-yl)-3-(3(4-nitrophenyl)-1-phenyl-1H-pyrazol-4-yl) acrylonitrile) 1f:

To a mixture of carbaldehyde $\mathbf{1 d}(0.5 \mathrm{~g}, 1.7 \mathrm{mmol})$ in methanol $(5 \mathrm{ml})$, was added $(0.27 \mathrm{~g}, 1.7 \mathrm{mmol})$ of benzimidazolyl acetonitrile 1e. Then added dropwise, piperidine $(0.17 \mathrm{ml}, 1.7 \mathrm{mmol})$ to the reaction mixture and continued stirring at $60{ }^{\circ} \mathrm{C}$ for $6 \mathrm{~h}$. It was then poured into water after cooling. $\mathrm{K}_{2} \mathrm{CO}_{3}$ (saturated) was then added till neutralization. The precipitate thus resulted was filtered and recrystallized from ethanol, after washed with water and dried, to afford pure target acrylonitrile 1f. Yield, $86 \%$; MP: 336-337 ${ }^{\circ} \mathrm{C}$; FT-IR $\left(\mathrm{KBr}, \mathrm{cm}^{-1}\right): v$ 3305.9, 2218.1, 1595.1, $1521.8,1423.5,1348.2,1232.5,1109.1,1068.6$, 960.6, 862.2, 817.8, 758.0, 684.7, 636.5, 497.6; ${ }^{1} \mathrm{H} \mathrm{NMR}(400 \mathrm{MHz}$, $\left.\mathrm{CDCl}_{3}\right): \delta 8.85(\mathrm{~s}, 1 \mathrm{H}), 8.23(\mathrm{dd}, J=8 \mathrm{~Hz}, 4 \mathrm{H}), 8.06(\mathrm{~s}, 1 \mathrm{H})$, $8.04(\mathrm{~s}, 1 \mathrm{H}), 7.77-7.73(\mathrm{~m}, 5 \mathrm{H}), 7.52-7.48(\mathrm{~m}, 3 \mathrm{H}),, 7.28(\mathrm{~s}$, $1 \mathrm{H}) ;{ }^{13} \mathrm{C}$ NMR $\left(100 \mathrm{MHz}, \mathrm{CDCl}_{3}\right): \delta 180.4,136.1,135.9$, 131.0, 130.6, 129.6, 129.3, 128.9, 123.9 .

\section{Computational details}

The entire set of calculations of $\mathbf{6}$ has been made by exploiting DFT-B3LYP (6-311G (d,p) method [Gaussian 09 program] [31]. The DFT-B3LYP is a universally accepted cheap method of computation for structural optimization [32]. Optimized molecular geometry, HOMO-LUMO energy calculations, MEP, Mulliken atomic charge distributions and NLO properties of the compound $\mathbf{6}$ were acquired from the above computational method.

\section{RESULTS AND DISCUSSION}

\section{A. Synthesis and characterization}

The condensation of p-nitro acetophenone with phenyl hydrazine under acidic condition using glacial acetic acid gave the intermediate 1c which on simultaneous cyclization and formylation using Vilsmeier-Haack reagent rendered 1d. Knoevenagel condensation of $1 \mathrm{~d}$ with active methylene group of $1 \mathrm{e}$ yielded the target compound $1 \mathrm{f}$ as shown in Scheme 1. The $1 \mathrm{~d}$ formation was confirmed by comparing with reported melting point. Further, the structure of target compound was confirmed based on following spectroscopic methods. In the IR spectrum, a strong carbonyl peak corresponding to aldehyde group of $1 \mathrm{~d}$ was absent. In addition, a medium peak observed at $2218 \mathrm{~cm}-1$ confirms the existence of nitrile group in 1f. A total of 15 protons viz aromatic protons, alkene proton and $\mathrm{NH}$ protons were observed between $\delta$ 7.28-8.85 ppm in the $1 \mathrm{H}$ NMR spectrum. Additionally, appearance of four protons with doublet of doublet splitting pattern at $\delta 8.23$ ppm supports the presence of nitro substituent at para position of phenyl moiety. ${ }^{13} \mathrm{C}$ NMR spectrum also appeals with the structure of $\mathbf{1 f}$.

\section{B. Computational details}

The Gaussian 09 program package [27] was used for complete theoretical calculations of the synthesized molecule 1f. As specified in the literature, the lucrative DFT, with B3LYP correlation function [28], approach have been deployed for the optimization of structure and determination of associated quantum chemical parameters viz., energy gaps of FMOs, MEPs, Mulliken atomic charge distributions and plausible NLO properties of target compound $\mathbf{1 f}$.

\section{Optimized geometry}

The ground state optimized geometry of heterocyclic compound 1f is showed in Figure 1. As exposed, the geometry of the pyrazole structural decoration has a typical butterfly form. The calculated bond lengths and bond angles of optimized structure of $\mathbf{1 f}$ obtained via DFT/B3LYP [6-311G (d,p)] are given in Tables 1 \& 2 .
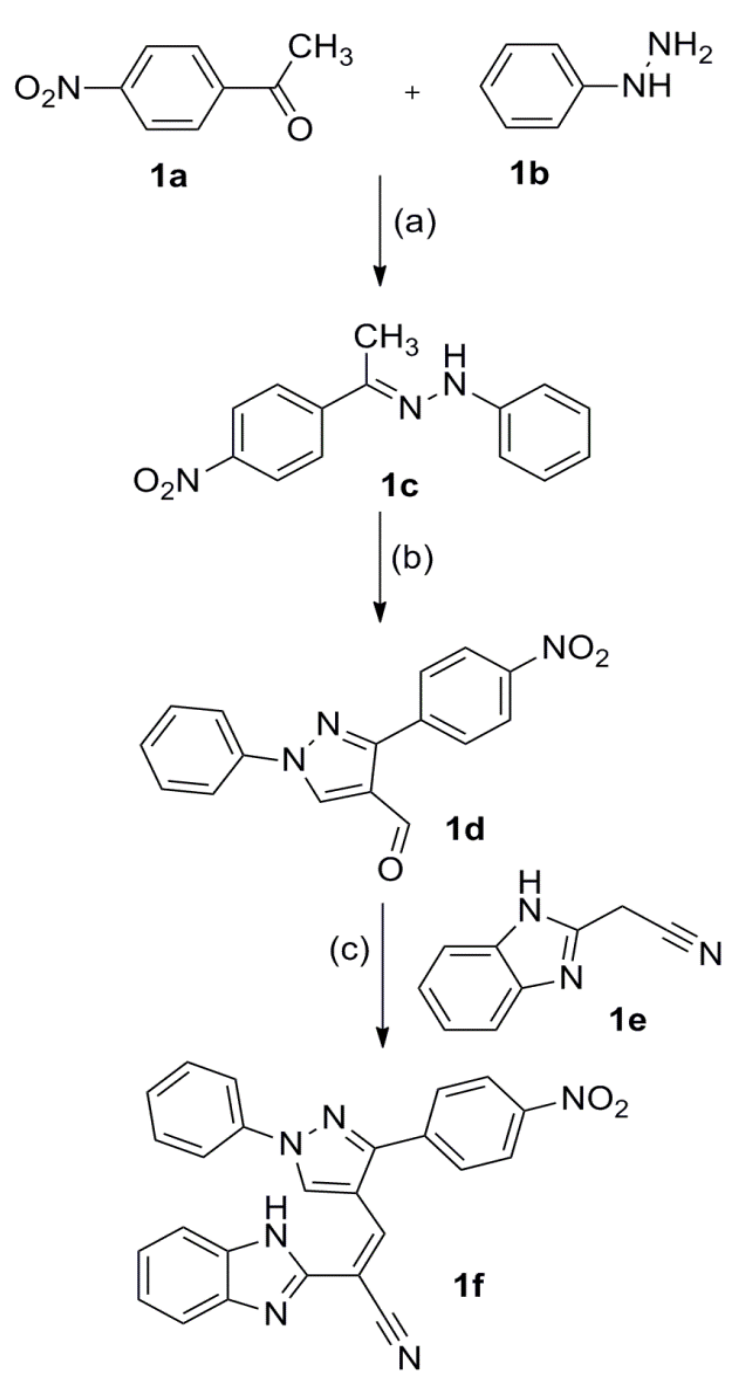

Scheme 1: Synthesis of compound 1f; Reagents and conditions: (a) Glacial acetic acid, reflux, 30 mins; (b) $\mathrm{DMF}^{-\mathrm{POCl}_{3}, 70-80}{ }^{\circ} \mathrm{C}, 6 \mathrm{~h}$; (c) piperidine, methanol, 60 ${ }^{\circ} \mathrm{C}$, 6 h. 

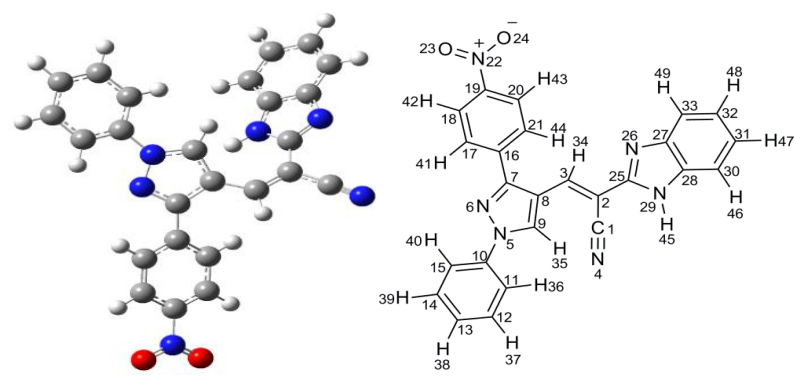

Figure 1. Optimized Structure of 2-(1H-benzo[d]imidazol-

2-yl)-3-(3-(4-nitrophenyl)-1-phenyl-1H-pyrazol-4-yl) acrylonitrile (1f).

Table 1: Bond length values of 1f

\begin{tabular}{lclc}
\hline Bond length & $[\AA]]$ & Bond length & {$[\AA ̊]$} \\
\hline C1-C2 & 1.4339 & C17-C18 & 1.3857 \\
C2-N4 & 1.1547 & C17-H41 & 1.0818 \\
C2-C3 & 1.3598 & C18-C19 & 1.3917 \\
C2-C25 & 1.4676 & C18-H42 & 1.0810 \\
C3-C8 & 1.4521 & C19-C20 & 1.3889 \\
C3-H34 & 1.0851 & C19-N22 & 1.4788 \\
N5-N6 & 1.3513 & C20-C21 & 1.3894 \\
N5-C9 & 1.3566 & C20-H43 & 1.0809 \\
N5-C10 & 1.4255 & C21-H44 & 1.0824 \\
N6-C7 & 1.3300 & N22-O23 & 1.2234 \\
C7-C8 & 1.4366 & N22-O24 & 1.2236 \\
C7-C16 & 1.4706 & C25-N26 & 1.3826 \\
C8-C9 & 1.3883 & C25-N29 & 1.3127 \\
C9-H35 & 1.0762 & N26-C27 & 1.3811 \\
C10-C11 & 1.3960 & N26-H45 & 1.0071 \\
C10-C15 & 1.3954 & C27-C28 & 1.4155 \\
C11-C12 & 1.3917 & C27-C33 & 1.3949 \\
C11-H36 & 1.0828 & C28-N29 & 1.3805 \\
C12-C13 & 1.3927 & C28-C30 & 1.3999 \\
C12-H37 & 1.0836 & C30-C31 & 1.3866 \\
C13-C14 & 1.3938 & C30-H46 & 1.0829 \\
C13-H38 & 1.0834 & C31-C32 & 1.4089 \\
C14-C15 & 1.3904 & C31-H47 & 1.0837 \\
C14-H39 & 1.0837 & C32-C33 & 1.3895 \\
C15-H40 & 1.0808 & C32-H48 & 1.0839 \\
C16-C17 & 1.4053 & C33-H49 & 1.0838 \\
C16-C21 & 1.4036 & & \\
\hline & & &
\end{tabular}

Table 2: Bond angle of 1f

\begin{tabular}{lccc}
\hline \multicolumn{1}{c}{ Bond Angle } & {$\left[{ }^{\circ}\right]$} & Bond Angle & {$[$ ㅇ] } \\
\hline C2-C1-N4 & 177.8798 & C19-C18-H42 & 119.4229 \\
C1-C2-C3 & 117.4229 & C18-C19-C20 & 121.8336 \\
C1-C2-C25 & 115.0213 & C18-C19-N22 & 119.0751 \\
C3-C2-C25 & 127.5436 & C20-C19-N22 & 119.0904 \\
C2-C3-C8 & 129.2947 & C17-C16-C21 & 118.8252 \\
C2-C3-H34 & 115.7885 & C16-C17-C18 & 120.8427 \\
C8-C3-H34 & 114.8589 & C16-C17-H41 & 119.0473 \\
N6-N5-C9 & 111.9743 & C18-C17-H41 & 120.1095 \\
N6-N5-C10 & 120.3856 & C17-C18-C19 & 118.8600 \\
C9-N5-N10 & 127.6380 & C17-C18-H42 & 121.7160 \\
N5-N6-C7 & 105.8819 & C19-C18-H42 & 119.4229 \\
N6-C7-C8 & 110.9101 & C18-C19-C20 & 121.8336 \\
N6-C7-C16 & 119.7304 & C18-C19-N22 & 119.0751 \\
C8-C7-C16 & 129.3589 & C20-C19-N22 & 119.0904 \\
C3-C8-C7 & 127.3516 & C19-C20-C21 & 118.8131 \\
C7-C8-C9 & 103.7824 & C19-C20-H43 & 119.5371
\end{tabular}

121.6470

120.8212

120.2347

118.9249

117.5609

117.4861

124.9530

123.4813

112.5377

107.1024

126.8872

104.5681

132.9581

122.4738

110.2853

119.8639

105.5026

117.9500

120.0732

121.9765

121.4207

119.6002

118.9788

121.6926

119.1467

119.1605

116.5982

121.2916

\section{Analysis of Mulliken population}

Mulliken population method yields the net atomic charge distribution of specific atoms in a molecule and thereby, the acceptor and donor pairs connecting the charge transfer in the molecule can be established [33, 34]. MEP analyses of 6 was attained from the optimized structural calculation and the results are given in Table 3 . The apparent atomic charge distribution of compound 6 is represented by coloring in Fig. 2. The net atomic charge distribution of compound is shown in Fig. 2. The output clearly indicates that the atom C24 of benzimidazole ring has got more positive charge due to electron-withdrawing character of nitrile moiety attached to the adjacent carbon atom and two neighboring electronegative nitrogen atoms. Also, the $\mathrm{C} 7$ atom of pyrazole ring holds almost nearer positive charge as that of C24 due to adjacent nitrogen atom, whereas the nitrogen N25 showed greater negative charges.

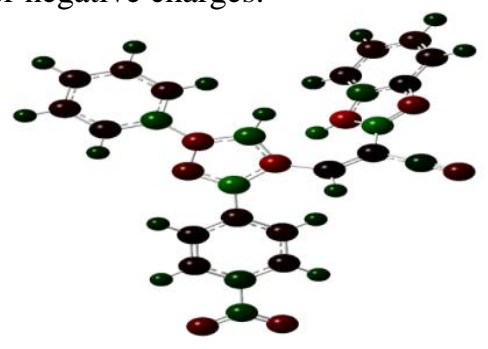

Figure. 2. Mulliken charge distribution of 2-(1H-benzo[d] imidazol-2-yl)-3-(3-(4- nitrophenyl)-1-phenyl1H-pyrazol-4-yl) acrylonitrile (1f)

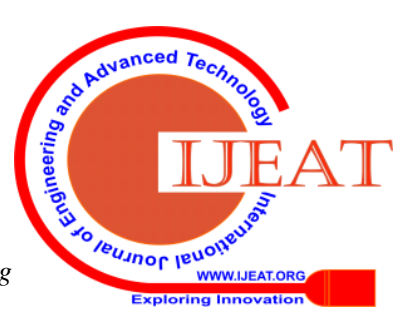




\section{Benzimidazole Structural Motifs}

Table 3. Mulliken atomic charges of 1f

\begin{tabular}{llll}
\hline Atom & \multicolumn{1}{c}{ Charges } & Atom & \multicolumn{1}{c}{ Charges } \\
\hline C1 & 0.076475 & N26 & -0.465116 \\
C2 & -0.029706 & C27 & 0.186649 \\
C3 & -0.023334 & C28 & -0.017168 \\
N4 & -0.216381 & N29 & -0.318858 \\
N5 & -0.329740 & C30 & -0.058396 \\
N6 & -0.249079 & C31 & -0.102417 \\
C7 & 0.313347 & C32 & -0.107719 \\
C8 & -0.405728 & C33 & -0.057209 \\
C9 & 0.236549 & H34 & 0.145625 \\
C10 & 0.205013 & H35 & 0.142816 \\
C11 & -0.107281 & H36 & 0.114057 \\
C12 & -0.098275 & H37 & 0.107079 \\
C13 & -0.077375 & H38 & 0.106098 \\
C14 & -0.097568 & H39 & 0.107838 \\
C15 & -0.056514 & H40 & 0.128067 \\
C16 & -0.076202 & H41 & 0.115322 \\
C17 & -0.033525 & H42 & 0.138702 \\
C18 & -0.048086 & H43 & 0.141079 \\
C19 & 0.125532 & H44 & 0.119113 \\
C20 & -0.050625 & H45 & 0.247689 \\
C21 & -0.075754 & H46 & 0.105901 \\
N22 & 0.170865 & H47 & 0.099362 \\
O23 & -0.265375 & H48 & 0.099343 \\
O24 & -0.265946 & H49 & 0.094272 \\
C25 & 0.306583 & & \\
\hline & & & \\
\hline
\end{tabular}

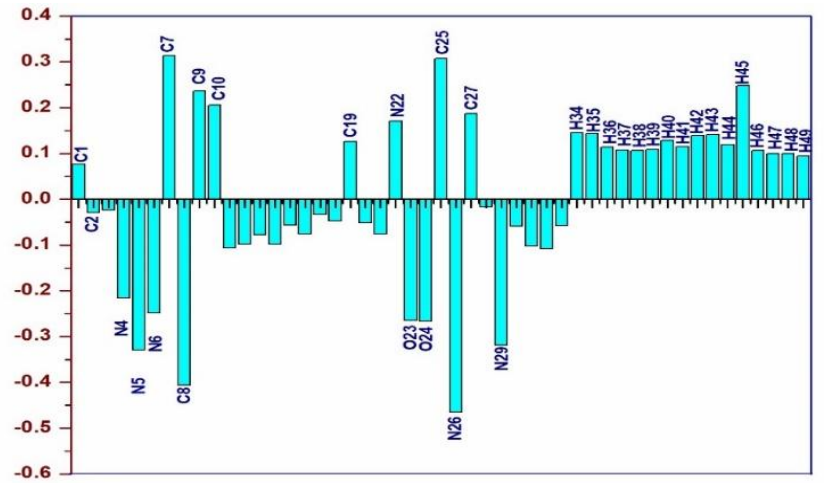

Figure. 3. Mulliken charge distribution chart of 2-(1H-benzo[d]imidazol-2-yl)-3-(3-(4-nitrophenyl)-1-phe nyl-1H-pyrazol-4-yl) acrylonitrile (1f)

\section{E. Frontier Molecular orbital Analysis}

The symmetry and energies of fmos such as homo-lumo orbitals predicts feasibility and kinetic stability of a reaction. also, the electronic spectra of a compound can be studied from fmo's energy values. as reported, the difference in energy between lumo and homo orbitals is a vigorous factor for the molecules' excitability determination as well as the topological resonance energy determination [31]. the $3 \mathrm{~d}$ plots of FMO's of the title compound are displayed in figure. 4. molecular orbital energy differences of HOMO-2-LUMO+2, HOMO-1-LUMO+1 and HOMO-LUMO, energy levels are tabulated in table 4. Comparatively large energy gap between homo-lumo orbitals indicates that title compound $\mathbf{1 f}$ has good stability and high chemical hardness. locations of frontier orbital as pictured in figure 4 suggest the probability of inter-electron transfer to occur within the molecule.

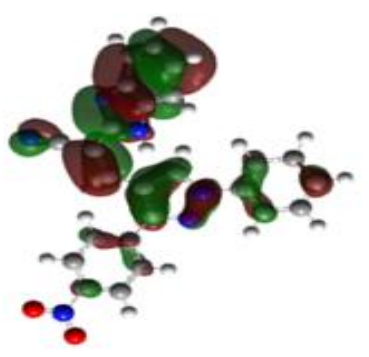

HOMO

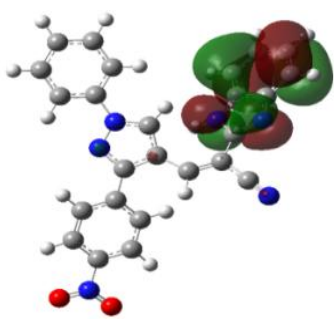

HOMO-1

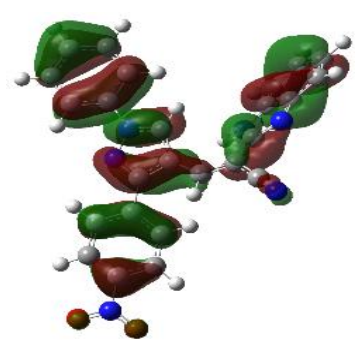

HOMO-2

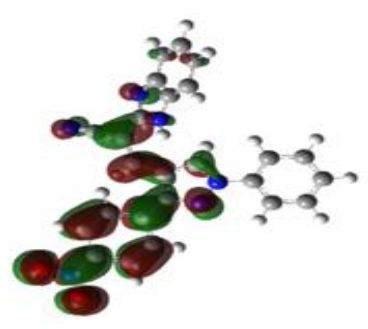

LUMO

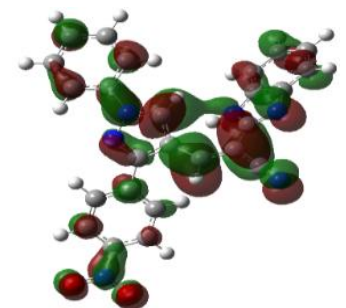

$\mathrm{LUMO}+1$

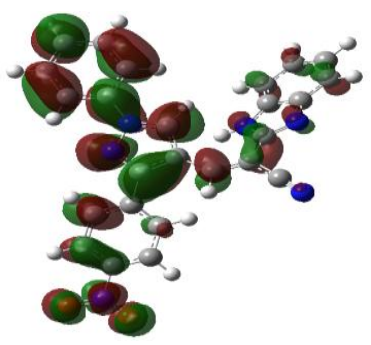

$\mathrm{LUMO}+2$
Fig. 4. Frontier Molecular Orbitals of $1 f$

Table 4. FMO's energies of 1f

\begin{tabular}{ll}
\hline Parameters & eV \\
\hline HOMO & -6.4347 \\
LUMO & -2.9255 \\
$\Delta \mathrm{E}$ & 3.5092 \\
HOMO-1 & -6.8083 \\
LUMO+1 & -2.6362 \\
$\Delta \mathrm{E} 1$ & 4.1721 \\
HOMO-2 & -7.0761 \\
LUMO+2 & -1.6365 \\
$\Delta \mathrm{E} 2$ & 5.4396 \\
\hline
\end{tabular}

\section{F. Molecular electrostatic potential analysis}

The electrostatic potential is a very populous tool for the determination of reactive sites, intermolecular association, interaction of hydrogen bonding and physicochemical affairs [32]. The MEP is very supportive to considerate the responsive locations for nucleophilic and electrophilic attack [33]. A MEP study of compound $\mathbf{1 f}$ has been prosecuted by DFT/B3LYP method to analyze and predict the reactive sites on the molecule. The positive (blue) region of the MEP is related to nucleophilic reactive centres and the negative (brown and yellow) regions correspond to electrophilic reactive centres. The electrostatic potential (isosurfaces) ranges from -0.170 to $+0.170 \mathrm{kcal} / \mathrm{mol}$ (dark blue) indicating exceedingly electron-deficient region $\left(\mathrm{V}_{(\mathrm{r})}>+0.107 \mathrm{kcal} / \mathrm{mol}\right)$ and brown denoting electron rich region $\left(\mathrm{V}_{(\mathrm{r})}>-0.107\right.$ $\mathrm{kcal} / \mathrm{mol}$ ). Model of

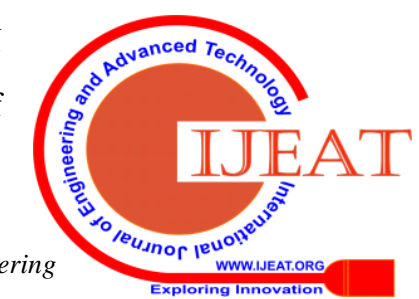


electrostatic potential and electron density are visualized in Figure 5. The highest positive region is located on the pyrazole ring with a value of $+0.170 \mathrm{kcal} / \mathrm{mol}$, indicatative of nucleophilic attacking site. Nitrogen of cyano and nitro are most reactive sites for nucleophilic and electrophilic attack, respectively.

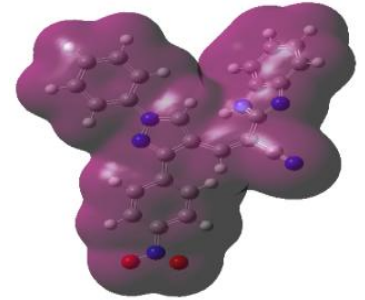

ED

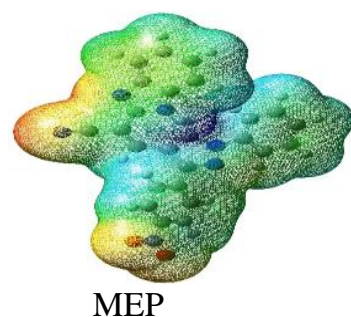

MEP

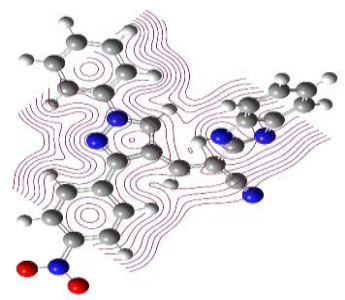

ED with contour

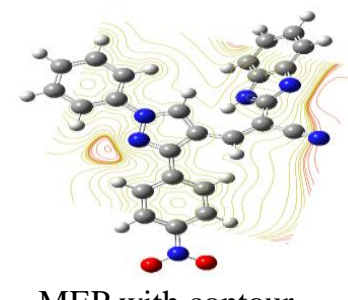

MEP with contour
Fig. 5. Molecular electrostatic potential map of 6

\section{G. Non-linear optical characteristics}

The parameters such as first order hyperpolarizability, polarizability as well as dipole moment have been computed by DFT. Comparison of values of the above-mentioned parameters with standard NLO materials parameters could suggest the existence of NLO properties of compound under investigation [34]. The first order hyperpolarizability, hyperpolarizability and dipole moment values of target molecule $\mathbf{1 f}$ are furnished in Table 5 .

The total hyperpolarizability $(\beta)$, polarizability and dipole moment values of compound $\mathbf{1 f}$ (calculated ones) was found to be $3.5214 \times 10^{-30}$ esu, $5.5840 \times 10^{-23}$ Debye-Ang, and 10.3052 Debye, respectively. In addition, on comparing the first order hyperpolarizability $(\beta)$ and dipole moment value of synthesized compound 1f with standard urea [35], it has been observed that the first order hyperpolarizability and dipole moment values are 9.5-fold and 1.4-fold greater than urea. The results suggest that the synthesized compound could either be useful for the non-linear optical crystal preparation or could serve as potential intermediate for the construction of better NLO materials.

Table 5. NLO Properties of $1 f$

\begin{tabular}{ll}
\hline \multicolumn{1}{c}{ Parameters } & Values \\
\hline Dipole moment & \\
$\mu_{\mathrm{x}}$ & -5.0710 \\
$\mu_{\mathrm{y}}$ & 8.6196 \\
$\mu_{\mathrm{z}}$ & 2.4868 \\
$\mu(\mathrm{D})$ & 10.3052 \\
Polarizability & \\
$\alpha_{\mathrm{xx}}$ & -217.2220 \\
$\alpha_{\mathrm{yy}}$ & -198.4763 \\
$\alpha_{\mathrm{zz}}$ & -195.6247
\end{tabular}

\section{CONCLUSION}

In conclusion, a novel heterocyclic acrylonitrile 1f was synthesized efficaciously by multistep synthetic approach. The structure elucidation of compound $\mathbf{1 f}$ was attained through physical and spectroscopic methods. The optimization of the molecule $\mathbf{1 f}$ was carried out computationally using DFT. Further, the HOMO-LUMO energy values, MEP, Mulliken Charge analysis and NLO properties of the molecule was also achieved through computational (DFT) method. Specifically, the results of NLO related parameters assure the better NLO properties than standard urea.

\section{ACKNOWLEDGMENT}

Financial assistance provided by the Indian Council of Medical research (No.58/16/2013-BMS), New Delhi, India is gratefully acknowledged.

\section{REFERENCES}

[1] H. Fu, J. Yao, "Size effects on the optical properties of organic nanoparticles," J. Am. Chem. Soc., vol. 123, pp. 1434-1439, Jan 2001.

[2] A. Anam, A. Abad, A. Mohd, Shamsuzzaman, "Review: biologically active pyrazole derivatives," New J. Chem., vol. 41, pp. 16-41, Nov 2016.

[3] S. A. H. El-Feky, Z. K. Abd El-Samii, N. A. Osman, J. Lashine, M. A. Kamel, H. K. Thabet, "Synthesis, molecular docking and anti-inflammatory screening of novel quinoline incorporated pyrazole derivatives using the Pfitzinger reaction II," Bioorg. Chem., vol. 58, pp. 104-116, Feb 2015.

[4] O. I. El-Sabbagh, M. M. Baraka, S. M. Ibrahim, C. Pannecouque, G. Andrei, R. Snoeck, J. Balzarini, A. A. Rashad, "Synthesis and antiviral activity of new pyrazole and thiazole derivatives," Eur. J. Med. Chem., 44, 3746-3753, Sep 2009.

[5] J. B. Shi, W. J. Tang, X. B. Qi, R. Li, X. H. Liu, "Novel pyrazole-5-carboxamide and pyrazole-pyrimidine derivatives: Synthesis and anticancer activity," Eur. J. Med. Chem., vol. 90, pp. 889-896, Jan 2015.

[6] D. M. Bailey, P. E. Hansen, A. G. Hlavac, E. R. Baizman, J. Pearl, A. F. DeFelice, M. E. Feigensonf, “3, 4-Diphenyl-1H-pyrazole1-propanamine antidepressants," J. Med. Chem., vol. 28, pp. 256-260, Feb 1985

[7] M. Mamaghani, R. Hossein Nia, F. Shirini, K. Tabatabaeian, M. Rassa, "An efficient and eco-friendly synthesis and evaluation of antibactrial activity of pyrano[2,3-c]pyrazole derivatives," Med. Chem. Res., 24, 1916-1926, May 2015.

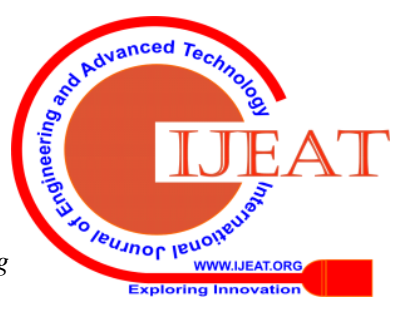




\section{Synthesis and Density Functional Theory Studies of Novel Heterocycle Tethered with Pyrazole and Benzimidazole Structural Motifs}

[8] R. C. Khunt, V. M. Khedkar, R. S. Chawda, N. A. Chauhan, A. R. Parikh, E. C. Coutinho, "Synthesis, antitubercular evaluation and 3D-QSAR study of N-phenyl-3-(4-fluorophenyl)-4-substituted pyrazole derivatives," Bioorg. Med. Chem. Lett., vol. 22, pp. 666-678, Jan 2012.

[9] B. Insuasty, A. Tigreros, F. Orozco, J. Quiroga, R. Abonia, M. Nogueras, A. Sanchez, J. Cobo, "Synthesis of novel pyrazolic analogues of chalcones and their 3-aryl-4-(3-aryl-4,5-dihydro1H-pyrazol-5-yl)-1-phenyl-1H-pyrazole derivatives as potential antitumor agents," Bioorg. Med. Chem., vol. 18, pp. 4965-4974, Jul 2010.

[10] C. B. Sangani, D. C. Mungra, M. P. Patel, R. G. Patel, "Synthesis and in vitro antimicrobial screening of new pyrano [4, 3-b] pyrane derivatives of 1H-pyrazole," Chin. Chem. Lett., vol. 23, pp. 57-60, Jan 2012.

[11] S. Mert, R. Kasimogullari, T. Ica, F. Colak, A. Altun and S. Ok, "Synthesis, structure-activity relationships, and in vitro antibacterial and antifungal activity evaluations of novel pyrazole carboxylic and dicarboxylic acid derivatives," Eur. J. Med. Chem., vol. 78, pp. 86-96, May 2014

[12] M. Wang, J. Zhang, J. Liu, C. Xu, H. Ju, "Intramolecular energy and charge transfer in 5-(9-anthryl)-3-(4-nitrophenyl)-1-phenyl2-pyrazoline," J. Lumin., vol. 99, pp. 79-83, Aug 2002.

[13] F. Karci, F. Karci, A. Demirçali, M. Yamaç, "Synthesis, solvatochromic properties and antimicrobial activities of some novel pyridone-based disperse disazo dyes," J. Mol. Liq., vol. 187, pp. 302-308, Nov 2013.

[14] X. C. Gao, H. Cao, L. Q. Zhang, B. W. Zhang, Y. Cao and C. H. Huang, "Properties of a new pyrazoline derivative and its application in electroluminescence," J. Mater. Chem., vol. 9, pp. 1077-1080, 1999.

[15] Burschka, F. Kessler, M. K. Nazeeruddin and M. Gratzel, "Co(III) complexes as p-dopants in solid-state dye-sensitized solar cells," Chem. Mater., vol. 25, pp. 2986-2990, June 2013.

[16] U. M. Kauhanka and M. M. Kauhanka, "Synthesis of new liquid crystalline isoxazole-, pyrazole-and 2-isoxazoline-containing compounds," Liq. Cryst., vol. 33, pp. 121-127 August 2006.

[17] P.-T. Chou and Y. Chi, "Phosphorescent Dyes for Organic LightEmitting Diodes," Chem. Eur. J., vol. 13, pp. 380-395, Dec 2006.

[18] R. A. Senthil, J. Theerthagiri, J. Madhavan and A. K. Arof, "Influence of pyrazole on the photovoltaic performance of dye-sensitized solar cell with polyvinylidene fluoride polymer electrolytes," Ionics, vol. 22, pp. 425-433, Mar 2016.

[19] A. Wasim, F. K. Mohemmed, V. Garima, M. Shaquiquzzaman, M. A. Rizvi, H. M. Syed, A. Mymoona, A. M. Mumtaz, "Therapeutic evolution of benzimidazole derivatives in the last quinquennial period," Eur. J. Med. Chem, vol. 126, pp. 705-753, Jan 2017.

[20] Z. Zhang, K. K. Ojo, S. M. Johnson, E. T. Larson, P. H. J. A. Geiger, A. C. Gonzalez, A. C. White, M. Parsons, E. A. Merritt, D. J. Maly, C. L. M. J. Verlinde, W. C. V. Voorhis, E. Fan, "Benzoylbenzimidazole-based selective inhibitors targeting Cryptosporidium parvum and Toxoplasma gondii calcium-dependent protein kinase-1," Bioorg. Med. Chem. Lett., 22, 2012, 5264-5267, Sep 2012.

[21] C. W. Evans, C. Atkins, A. Pathak, B. E. Gilbert, J. W. Noah, "Benzimidazole analogs inhibit respiratory syncytial virus $\mathrm{G}$ protein function," Antiviral Res., vol. 121, pp. 31-38, Sep 2015.

[22] Q. Chen, W. Tian, G. Han, J. Qi, C. Zheng, Y. Zhou, L. Ding, J. Zhao, J. Zhu, J. Lv, C. Sheng, "Design and synthesis of novel benzoheterocyclic derivatives as human acrosin inhibitors by scaffold hopping," Eur. J. Med. Chem., vol. 59, pp. 176-182, Jan 2013.

[23] J. F. Rossignol, H. Maisonneuve, "Benzimidazoles in the treatment of trichuriasis: a review," Ann. Trop. Med. Parasitol, vol. 78, pp.135-144, Apr 1984.

[24] K. Dubey, P. K. Sanyal, "Benzimidazoles in a wormy world," Online Vet. J., vol. 5, pp. 63, 2010.

[25] H. Akpınar, A. Balan , D. Baran , E. K. Ünver , L. Toppare, "Donor-acceptor-donor type conjugated polymers for electrochromic applications: benzimidazole as the acceptor unit," Polymer, 2010, vol. 51, pp. 6123-6131, Dec 2010.

[26] S. Bansal, M. Bala, S. K. Suthar, S. Choudhary, S. Bhattacharya' V. Bhardwaj, S. Singla, A. Joseph, "Design and synthesis of novel 2-phenyl-5-(1, 3-diphenyl-1H-pyrazol-4-yl)-1, 3, 4-oxadiazoles as selective COX-2 inhibitors with potent anti-inflammatory activity," Eur. J. Med. Chem., vol. 80, pp. 167-174, Jun 2014.
[27] M. J. Frisch, G. W. Trucks, H. B. Schlegel, G. E. Scuseria, M. A. Robb, J. R. Cheeseman, et. al, Gaussian Inc, Wallingford CT, Gaussian 09, Revision D.01, 2009.

[28] C. Lee, W. Yang, R.G. Parr, "Development of the Colle-Salvetti correlation-energy formula into a functional of the electron density," Phys. Rev. B., vol. 37, pp. 785-789, Jan 1988.

[29] R. S. Mulliken, "Electronic Population Analysis on LCAO-MO Molecular Wave Functions. I," J. Chem. Phys., 1955, vol. 23, pp. 1833-1840, December 1955.

[30] R. S. Mulliken, "Molecular Compounds and Their Spectra. V. Orientation in Molecular Complexes," J. Chem. Phys., vol. 23, pp. 1841-1846, December 1955.

[31] I. Fleming, "Frontier Orbitals and Organic Chemical Reactions," Wiley-Blackwell, New York, 1976.

[32] S. Murray, K. Sen, "Molecular Electrostatic Potentials, Concepts and Applications," Elsevier, Amsterdam, 1996.

[33] P. Politzer, P. R. Laurence, K. Jayasuriya, "Molecular electrostatic potentials: an effective tool for the elucidation of biochemical phenomena," Environ. Health Perspect, vol. 61, pp. 191-202, Sep 1985.

[34] M. Nakano, I. Shigemoto, S. Yamada, K. Yamaguchi, "Size- consistent approach and density analysis of hyperpolarizability: Second hyperpolarizabilities of polymeric systems with and without defects," J. Chem. Phys., vol. 103, pp. 4175-4191, Jun 1995.

[35] Wu, J. G. Snijders, C. Lin, "Reinvestigation of hydrogen bond effects on the polarizability and hyperpolarizability of urea molecular clusters," J. Phys. Chem. B., vol. 106, pp. 8954-8958, Aug 2002.

\section{AUTHORS PROFILE}

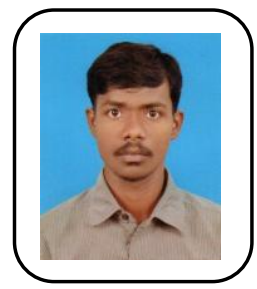

Ramar Sivaramakarthikeyan earned his BSc degree in Chemistry from VHNSN College, Virudhunagar, affiliated to Madurai Kamaraj University, Tamilnadu, India in 2013. He completed his MSc in Chemistry in 2015 from Kalasalingam Academy of Research and Education, Krishnankoil. Currently he is pursuing $\mathrm{PhD}$ at Kalasalingam Academy of Research and Education, Krishnankoil. He has been working in the area of biopertinent heterocycles.

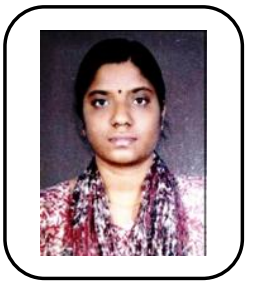

Krishnaraj Padmavathy received her Bachelor of Science degree in Chemistry from Bharathidasan college for women, Pondicherry in 2004. She obtained her Master's degree from Kanchi Mamunivar Centre for Postgraduate Studies, Pondicherry in 2006. She is currently a PhD student at Kalasalingam Academy of Research and Education, Krishnankoil, India. Her focus of research is methodology development and heterocyclic construction for biological applications.

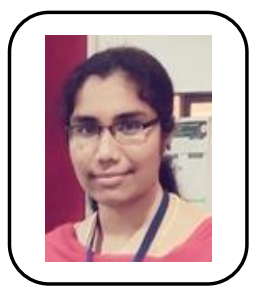

Shunmugam Iniyaval obtained her Bachelor of Science degree in Chemistry from Sri Parasakthi College for Women, Courtallam in 2013. She earned her Master's degree in Chemistry in 2015 from Sri Paramakalyani College, Alwarkuruchi. She is currently a $\mathrm{PhD}$ student at Kalasalingam Academy of Research and Education, Krishnankoil. She has been working in the area of heterocyclic synthesis and medicinal chemistry.

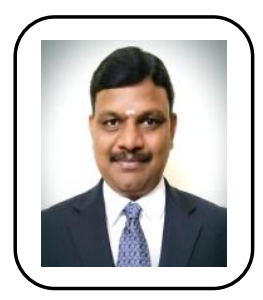

Dr. Chennan Ramalingan is serving as Professor of Chemistry at KARE. He received his $\mathrm{PhD}$ in Organic Chemistry from Annamalai University (2002). After he served as Research Professor at Kyungpook National University, South Korea followed by Assistant Professor a Osaka University, Japan (8 years), he joined at Kalasalingam Academy of Research and Education, Krishnankoil (2011). His research interests include organic synthesis, medicinal chemistry and material chemistry. He published more than 70 International research articles.

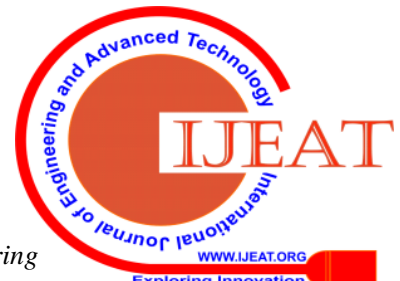
\& Sciences Publication 